\title{
The Status of Edible Mushrooms Resource Development and Nutrition Evaluation in Sichuan Province, China
}

\author{
Qian-Qian TANG ${ }^{1}$, Yu-Xian YOU ${ }^{1}$, Yi-Wen $\mathrm{LI}^{1}$, Si-Qi ZENG ${ }^{1}$, Di \\ $\mathrm{CHEN}^{1}$, Zhao SU${ }^{1}$, Ai-Ping LIU ${ }^{1}$, Hong CHEN $^{1}$, Chao-Hui FENG ${ }^{1}$, \\ Yao-Wen LIU ${ }^{1}$, Cheng LI', Yun-Tao LIU ${ }^{1,2, *}$ \\ ${ }^{1}$ College of Food Science, Sichuan Agricultural University, Yaan 625014, China \\ ${ }^{2}$ Animal Nutrition Institute, Sichuan Agricultural University, Chengdu 611130, China \\ ${ }^{*}$ Corresponding author
}

Keywords: Edible mushrooms, Nutrition, Development, Sichuan.

\begin{abstract}
With the development of our agriculture, the utilization of edible mushrooms is more and more widely recognized. The resources of them are abundant in our country, especially in Sichuan. They contain not only rich nutrients, but also active substances such as polysaccharides, which with the biological activity of anti-tumor, anti-diabetic, antifungal and anti-viral. Though edible mushrooms have become the polar industry of Sichuan, still many problems concerning the food safety of edible mushrooms need to be solved. This paper conducts a clear exposition of rich edible mushrooms resources and problems existing in processing and utilization of edible mushrooms in Sichuan.
\end{abstract}

\section{Introduction}

As national economy develops continuously and stably, especially in agriculture and rural economy, edible mushrooms industry as an important part of the agricultural industry in China today, has also grown and developed. The edible mushrooms' yield under 60,000 tons in 1978 , but had increase to $25,717,000$ tons in 2011 , and the production value more than 150 billion. We earn foreign exchange through export reach $\$ 2.4$ billion, becoming the largest edible mushrooms producing country and exporter in the world [1-3].

All the time, Sichuan is not only a major agricultural province in China, but also a great province of edible mushrooms resources. Since the $60 \mathrm{~s}$ and $70 \mathrm{~s}$ of the 20th century, Sichuan province have a large-scale cultivation of edible mushrooms, and then the varieties of them like Tremella fuciformis, Plearotus ostreatus, flammulina velutipes, et al. gradually spread. The edible mushrooms' yield in Sichuan increase 408,800 tons in 2002 to 1,005,000 in 2007, and the production value more than 5 billion yuan in 2010 (ranked $3^{\text {rd }}$ in the country) [3-6].

The distribution of the edible mushrooms resources can mainly divided into the following five: 1) Dayi, Mianzhu, Emei Mountain, Pengxi, Hongya, Xuanhan, et al. are the mushrooms-producing core areas; 2) Jintang, Zhongjiang, Shifang, Pixian, Jianyang, Dujiangyan, Qingbaijiang, et al. are the core areas of succeeded cultivation; 3) the core areas of anti-season mushrooms production are Hongyuan, Maerkang, Aba, et al. ; 4) Tongjiang, Nanjiang, Pingwu, Wanyuan, et al. are the traditional products of the mushrooms' core areas; 5) the rare wild mushroomsproducing core areas are Xichang, Daocheng, Xiangcheng, et al. Among them, the yield of edible mushrooms in Dayi, Jintang, Shifang, et al. is accounted for over $25 \%$ of the local agricultural production, becoming a mainstay of the local agricultural industry. Edible mushrooms have been 
classified as five big superiority characteristic agriculture industry in sichuan province [7-9].

\section{Chemical Composition and Nutritional Value of Edible Mushrooms}

\section{Resources Solid Contents, Major Components and Energy}

The solid contents of fresh edible mushrooms is very low, contenting of about $10 \%$ in the total solid content, mainly composed of carbohydrate, protein and trace elements. And edible mushrooms fruiting body contains about $90 \%$ water [1].

Generally, edible mushrooms are rich in carbohydrate, protein and fibre, while the fat content is very low. And the energy contained ordinary in the rage $1.2 \sim 1.8 \times 10^{4}$ $\mathrm{kJ} / \mathrm{kg}$. Recently, Liu and others analyzed Sichuan clitocybe maxima, catathelasma ventricosum, stropharia rugoso-annulata, craterellus and lepista nuda, their total enegy are $1736.59,1516.37,1726.11$ and $1580.33 \mathrm{~kJ} / 100 \mathrm{~g}$ [1].

\section{Carbohydrates}

Carbohydrates play the role of providing energy in food. The easily digestible carbohydrates in edible mushrooms includes mannitol $(0.3 \% \sim 5.0 \%)$ [2], glucose $(0.5 \% \sim 3.6 \%)[3]$ and glycogen $(1.0 \% \sim 1.6 \%)$; the indigestible carbohydrates account for the most of the total amount of carbohydrates, mainly includes oligose and non-starch polysaccharides (chitin, $\beta$-glucan, mannan). The range of carbohydrates content in edible mushrooms is enormous, according to the data repoted previously, the range varies from $13 \%$ to $65 \%$.

\section{Protein and Amino acid}

To estimate the nutritional value of edible mushrooms we mainly considered protein content. The Food and Agriculture Organization (FAO) believe that the nutritional value of protein edible mushrooms higher than that of plant protein. Generally speaking, the content of edible mushrooms protein is $12 \% \sim 29.3 \%$ [4]. Yin and Zhou's research suggest that edible mushrooms of amino acid equivalent to or better than soyabean protein [5], even some studies report that edible mushrooms of amino acid can be comparable to the egg. According to the FAO/WHO (1973) standards, in order to keep the intake of protein, they recommends eating essential amino acid and non-essential amino acid ratio above 0.6 .

\section{Mineral elements}

Edible mushrooms fruiting body can not only concentration of a large number of macroelements and microelements, but also enrich with heavy metal elements mercury $(\mathrm{Hg})$, cadmium $(\mathrm{Cd})$, lead $(\mathrm{Pb})$, et al. Potassium $(\mathrm{K})$ and phosphorus $(\mathrm{P})$ are two largest element contents in general in edible mushrooms, the following element contents are calcium $(\mathrm{Ca})$, magnesium $(\mathrm{Mg})$, sodium $(\mathrm{Na})$ and iron $(\mathrm{Fe})$ [6]. The content of $\mathrm{K}$ in edible mushrooms range 16,000 to $37,000 \mathrm{mg} / \mathrm{kg}$, P range 4,820 to $19,000 \mathrm{mg} / \mathrm{kg}$. Liu, et al. recently reported 5 kinds of edible mushrooms' toxic heavy metal content in Sichuan: the Cd content in the range of 0.29 to $2.07 \mathrm{mg} / \mathrm{kg}$; the $\mathrm{Pb}$ content in the range of 0.07 to $1.44 \mathrm{mg} / \mathrm{kg}$. All in all, picking the heavy metal content of edible mushroom in urban or industrial areas are often higher than the wild countryside picked [6]. 


\section{Major Functions and Activity Ingredients of Edible Mushrooms}

\section{Anti-tumor}

The extracts of edible mushrooms are widely reported with anti-tumor activity. It is always considered that $\beta$-glucan, mannan in edible mushrooms is the key to the anti-tumor activity, which not kill tumor cells by side effects, but by raising the cell immunity to implement the tumor inhibition. Recent research has shown that patients significantly improve the activity of NK cells and IgG, IgM, neutrophils, and the number of white blood cells and inhibit the aromatase activity at the same time after taking the edible mushrooms polysaccharide, and achieve the tumor treatment in the end [8]. There are also the research report that estrogen-receptor-positive breast cancer patients after taking the edible fungus extract could inhibit the aromatase activity in the body, so as to decrease the level of estrogen.

\section{Anti-diabetic}

Diabetes is a common comprehensive chronic metabolic disease. Many research results show that with $\beta$-glucan, mannan structure of edible mushroom polysaccharides have the ability to restore the pancreas function to promote the $\beta$ cells secrete insulin and improve the sensitivity of the peripheral tissue [9]. Edible mushrooms in addition to a balanced amount of nutrients (protein, fat, and carbohydrates), also contain numerous antioxidant activity of micronutrients (vitamins) and the non-nutritive substance (polyphenols) [1]. These edible mushrooms of the active material can make the liver, pancreas and other organs function of diabetics return to normal [10], which promote the secretion of insulin and related hormones, making the body's metabolic function recovery. Up to now, many hypoglycemic activity edible mushrooms have been reported, such as the agaricus bisporus, agaricus, cordyceps sinensis, coprinus comatus, chaga, et al. [11].

\section{Antifungal}

Numerous studies have shown that edible mushrooms and their extract has the gram negative/positive activity of bacteria, yeast and filamentous fungi Numerous studies have shown that edible fungi and its extract has the activity to resistance of gram negative/positive, yeast and filamentous fungi [12]. Bernardshaw, et al. studies have demonstrated that agaricus blazei murill extract can kill pneumococcus $6 \mathrm{~B}$ in mice [13]. The same research team gave mice agaricus blazei murill extract before the infection of bacterial sepsis in another study, the experimental results show that the agaricus blazei murill extract can significantly reduce the mortality of mice [14]. Martins, et al. research believe that edible mushrooms' antimicrobial activity are not a direct effects on bacteria, but through their own polysaccharide components activated macrophages of the host, so as to improve the body's resistance [15].

\section{Anti-viral}

Edible mushrooms protein, polypeptide and polysaccharide are widely reported to have antiviral activity. Reverse transcriptase and protease are the key enzymes of HIV-1 life cycle, and versicolor polysaccharides can inhibit their activity. And also some of ganoderma lucidum triterpenoid compounds with anti-HIV-1-protease activity [12]. Maitake mushroom extracts can inhibit the hepatitis $\mathrm{B}$, herpes simplex virus, and the active of the influenza virus. However, the antiviral activity of edible mushrooms mechanism is not fully clear, a lot of research is in its infancy. 


\section{Food Safety of Edible Mushrooms}

The ideal nutritional supplement source-edible mushrooms have been recommended for the 21st century's health food by the United Nations because of its richness protein, carbohydrate and kinds of minerals. On the society in recent years, a variety of food safety problems caused the attention of people, as "regulars" at the dinner table, edible mushrooms of safety problem has become the focus of attention. At present, the food safety problems of edible mushrooms are mainly in heavy metal pollution and pesticide pollution.

\section{Status of Heavy Metal Content in Edible Mushrooms}

Edible mushrooms enrichment of heavy metals start from the earliest mushroom (Agaricus) of cadmium enrichment. In cadmium element analysis of clitocybe gigantea, lactarius deliciosus, et al. a total of 34 kinds of wild mushrooms, found their average chromium content is 1.14 to $1.11 \mu \mathrm{g} / \mathrm{g}$ (up to 10 times of high chromium content than growing environment), and chromium element enrichment mainly in pileus. Liu, and others' study reported five kinds of wild edible mushrooms in Sichuan of cadmium, lead and arsenic content. Although the three heavy metals were detected, their levels are lower than the safety standards set by the commission of the European Economic Community. It is worth noting that Kalac think the risk of heavy metal content exceeds bid in artificial cultivation of edible mushrooms is very low. Although the main heavy metals lead, mercury, picks, arsenic in edible mushrooms are higher than that of green plants, different species, different cultivation conditions, different harvest time, et al. can all influence the edible mushrooms enrichment degree and the content of heavy metals [13].

\section{Status of Pesticide Pollution in Edible Mushrooms}

As an agricultural country, in order to ensure the crop production, our country each year about 240,000 tons of crops, processed into more than 1,500 kinds of pesticide formulations which are seriously polluted water, air and soil. Organophosphorus and pyrethroid pesticides is the prevention and control of pests commonly used pesticides in the production of edible mushrooms, and chlorothalonil and carbendazim are also effective drugs for a variety of miscellaneous bacteria. Although the chemical structure of organophosphorus and pyrethroid pesticides contained many unstable ester bonds, carbendazim and chlorothalonil are also low in toxicity pesticides, edible mushrooms under the condition of low temperature and high humidity, which makes these toxic substances in a relatively stable environment, and edible mushrooms production cycle is short, therefore they easy to remain in the fruiting body. According to the general administration of customs statistics, China's exports of 382,100 tons of edible fungus products, value $\$ 463$ million in 2002 , down $16.11 \%$ and $17.95 \%$ respectively compared to the same. In January to August 2003, the country lentinula edodes exports fell 17\% year on year, the main reason is caused by pesticide residues of the green barriers [15].

\section{Conclusions}

Nowadays, Edible mushrooms have become a research hotspot, on its research direction are also continuously widened. However, our understanding of edible mushrooms is still not comprehensive, which make us to evaluate the nutritional value of credible is very limited. Edible fungus food safety problems in terms of heavy metal enrichment, using its ability to enrichment to gathering trace elements necessary for human are a new breakthrough. Moreover, edible mushrooms' Composition is 
complicated, its function also showed a trend of diversification, and the different compositions of the edible fungus functional characteristics and the differences between different physiological activity of different mushrooms similar material research, should also be an important area of nutrition research of edible mushrooms.

\section{Acknowledgement}

This research was financially supported by China Postdoctoral Science Foundation (No. 2015M580795), Fund Project of Sichuan Provincial Department of Education (16ZB0053) and Scientific Research Foundation of Sichuan Agricultural University (No. 06021400).

\section{References}

[1] Y.T. Liu, J. Sun, Z.Y. Luo, S.Q. Rao, et al., Chemical composition of five wild edible mushrooms collected from Southwest China and their antihyperglycemic and antioxidant activity, J. Food Chem. Toxicol. 50 (2012) 1238-1244.

[2] J.A. Vaz, L. Barros, A. Martins, C. Santos-Buelga, et al., Chemical composition of wild edible mushrooms and antioxidant properties of their water soluble polysaccharidic and ethanolic fractions, J. Food Chem. 126 (2011) 610-616.

[3] M.Y. Kim, L.M. Chung, S.J. Lee, Comparison of free amino acid, carbohydrates concentrations in Korean edible and medicinal mushrooms, J. Food Chem. 113 (2009) 386-393.

[4] P.C.K. Cheung, The nutritional and health benefits of mushrooms, J. Nutr. Bull. 35 (2010) 292-299.

[5] J.Z. Yin, L.X. Zhou, Analysis of nutritional components of 4 kinds of wild edible fungi in Yunnan, J. Food Res. Develop. 29 (2008) 133-136.

[6] J. Falandysz, J. Borovicka, Macro and trace mineral constituents and radionuclides in mushrooms-health benefits and risks, J. Appl. Microbiol. Biotechnol. 97 (2013) 477-501.

[7] J.E. Ramberg, E.D. Nelson, R.R. Sinnott. Immunomodulatory dietary polysaccharides: A systematic review of the literature, J. Nutr. Bull. 9 (2010).

[8] A. Misra, M.S. Lalan, V.K. Singh, et al., Role of natural polysaccharides in treatment and control of diabetes, Chemistry and medicinal value book series, J. Recent Progr. Med. Plants 25 (2009) 347-373.

[9] B.A. Wani, R.H. Bodha, A.H. Wani, Nutritional and medicinal importance of mushrooms, J. Med. Plants Res. 4 (2010) 2598-2604.

[10] S.C. Jeong, Y.T. Jeong, B.K. Yang, et al., White button mushroom (Agaricus bisporus) lowers blood glucose and cholesterol levels in diabetic and hypercholesterolemic rats, J. Nutr. Res. 30 (2010) 49-56.

[11] R. Hearst, D. Nelson, G. McCollum, et al., An examination of antibacterial and antifungal properties of constituents of Shiitake (Lentinula edodes) and oyster (Pleurotus ostreatus) mushrooms, J. Complement Ther. Clin. Pract. 15 (2009) 5-7. 
[12] S. Bernardshaw, G. Hetland, L.K. Ellertsen, et al., An extract of the medicinal mushroom Agaricus blazei Murill differentially stimulates production of pro-inflammatory cytokines in human monocytes and human vein endothelial cells in vitro, J. Inflammation 29 (2005) 147-153.

[13] P.R. Martins, M.C. Gameiro, L. Castoldi, et al. Polysaccharide-rich fraction of Agaricus brasiliensis enhances the Candidacidal activity of murine macrophages, J. Memorias Do Instituto Oswaldo Cruz 103 (2008) 244-250.

[14] R.S. el Dine, A.M. el Halawany, C.M. Ma, et al. Anti-HIV-1 protease activity of lanostane triterpenes from the vietnamese mushroom Ganoderma colossum, J. Nat. Prod. 71 (2008) 1022-1026.

[15] Kalač P, Chemical composition and nutritional value of European species of wild growing mushrooms: A review, J. Food Chem. 113 (2009) 9-16. 